\title{
Change of Mandibular Position during Two-Phase Orthodontic Treatment of Skeletal Class II in the Chinese Population
}

\author{
Rhonda Nga Yi Cheung, ${ }^{1}$ Urban Hägg, ${ }^{1}$ Ricky Wing Kit Wong, \\ Chongshan Liao, ${ }^{1}$ and Yanqi Yang ${ }^{1}$ \\ ${ }^{1}$ Orthodontics, Faculty of Dentistry, The University of Hong Kong, 34 Hospital Road, Sai Ying Pun, Hong Kong \\ ${ }^{2}$ Department of Dentistry \& Maxillofacial, United Christian Hospital, Kowloon, Hong Kong \\ Correspondence should be addressed to Yanqi Yang; yangyanq@hku.hk
}

Received 22 July 2014; Accepted 20 October 2014

Academic Editor: Mehmet Ozgur Sayin

Copyright (C) 2015 Rhonda Nga Yi Cheung et al. This is an open access article distributed under the Creative Commons Attribution License, which permits unrestricted use, distribution, and reproduction in any medium, provided the original work is properly cited.

\begin{abstract}
The aim of this study was to evaluate the change in mandibular position during a two-phase orthodontic treatment of skeletal Class II malocclusion. Thirty consecutively treated Chinese male adolescents who had undergone two-phase treatment with Herbst appliance and fixed appliance and fulfilled the specific selection criteria were sampled. Cephalograms taken at T0 (before treatment), T1 (at the end of functional appliance treatment), and T2 (at the end of fixed appliance treatment) were analyzed. The change in sagittal positioning of the mandible was $6.8 \pm 3.44 \mathrm{~mm}$ in phase I (T0-T1), $0.4 \pm 2.79 \mathrm{~mm}$ in phase II (T1-T2), and $7.2 \pm 4.61 \mathrm{~mm}$ in total. The mandible came forward in $100 \%$ of the patients at T1. In phase II, it came forward in one-third (positive group) remained unchanged in one-third (stable group) and went backward in one-third (negative group) of the patients. At T2, it came forward twice as much in the positive group compared to the negative group. Mandibular length was significantly increased in $100 \%$ of the patients in both phases. In conclusion, during the treatment with functional appliance, the mandibular prognathism increases in all patients, whereas during the treatment with fixed appliance there is no significant change in mandibular prognathism.
\end{abstract}

\section{Introduction}

Ever since the introduction of functional appliances more than a century ago, their potential effects on modifying growth have been a matter of controversy. Based on prospective clinical trials some investigators claimed that they have demonstrated that functional appliances modify growth [15], whereas others meant that the effects were limited to the dentoalveolar process only [6-8]. However, the recent randomized clinical trials (RCTs) on treatment of Class II malocclusion seem to agree on that functional appliances do not influence the Class II pattern to a clinical significant degree [9], that is, marked forward positioning of the mandible. Moreover, when there eventually was an effect it was shortlived [10]. However, many studies reported that the mandible increased in length due to functional appliance treatment, and since the mandible was not markedly positioned forward, the likely effect was the increase of the lower face height [11].
The concept of RCT is considered the golden standard in the hierarchy of evidence [12] and has been used to evaluate the effect of functional appliances, such as one-phase versus two-phase treatment of Class II malocclusion [13-17]. However, others claimed that RCTs are not suitable in the orthodontic context [18]. For instance, are the cephalometric measurements chosen to evaluate the treatment changes and effects reliable, valid, and accurate? How are the many and various factors, such as research design, sampling methods, inclusion criteria, treatment and observation periods, methods used for evaluation, patient compliance, timing of the pubertal growth, operator's experience, and the choice of appliance, taken into account? The inherit complexity of the nature of the problems investigated with simple formulas in those RCT studies makes direct comparison of the results impossible. Subsequently, the obvious limitations of the recent RCTs on Class II treatment seem to provide inconclusive results again. 
TABLE 1: Age at the beginning of phase 1 (T0), end of phase 1/beginning of phase 2 (T1) and end of treatment (T2), and duration of the treatment phases of the study sample $(N=30)$ and the three subgroups $(n=10$ in each subgroup).

\begin{tabular}{|c|c|c|c|c|c|c|}
\hline & \multicolumn{3}{|c|}{ Average age (years ) } & \multicolumn{3}{|c|}{ Average time of treatment phases (years) } \\
\hline & T0 & $\mathrm{T} 1$ & $\mathrm{~T} 2$ & T0-T1 & T1-T2 & T0-T2 \\
\hline Whole study sample & $13.4 \pm 1.20$ & $14.5 \pm 1.20$ & $16.4 \pm 1.50$ & $1.1 \pm 0.20$ & $1.9 \pm 0.80$ & $3.0 \pm 0.90$ \\
\hline Positive group & $12.8 \pm 1.07^{\mathrm{ns}}$ & $13.9 \pm 1.12^{\mathrm{ns}}$ & $16.2 \pm 1.92^{\mathrm{ns}}$ & $1.1 \pm 0.27^{\mathrm{ns}}$ & $2.2 \pm 0.74^{\mathrm{ns}}$ & $3.3 \pm 0.82^{\mathrm{ns}}$ \\
\hline Stable group & $13.9 \pm 1.21^{\mathrm{ns}}$ & $15.0 \pm 1.17^{\mathrm{ns}}$ & $16.6 \pm 1.37^{\mathrm{ns}}$ & $1.1 \pm 0.26^{\mathrm{ns}}$ & $1.6 \pm 0.75^{\mathrm{ns}}$ & $2.7 \pm 0.87^{\mathrm{ns}}$ \\
\hline Negative group & $13.4 \pm 1.07^{\mathrm{ns}}$ & $14.5 \pm 1.08^{\mathrm{ns}}$ & $16.4 \pm 1.32^{\mathrm{ns}}$ & $1.1 \pm 0.25^{\mathrm{ns}}$ & $1.8 \pm 0.77^{\mathrm{ns}}$ & $3.0 \pm 0.85^{\mathrm{ns}}$ \\
\hline
\end{tabular}

SD: Standard deviation.

${ }^{n s}$ Non-significant, ${ }^{*} P<0.05,{ }^{* *} P<0.01,{ }^{* * *} P<0.001$.

Most of the previous studies on functional appliances have focused on single-phase treatment only [2, 19-25], despite, in the clinical situation, second phase of fixed appliance therapy is often necessary in order to obtain a proper alignment and occlusion of the dentition. However, few studies had been carried out on two-phase treatment [13, 26, 27], and the effects of fixed appliance on the skeletal and dental changes after the first phase functional appliance treatment have not been fully investigated. Therefore, the purpose of this study is to investigate the change in the mandibular position during each phase of a two-phase orthodontic treatment of skeletal Class II malocclusion.

\section{Materials and Methods}

2.1. Sample Selection. The sample was selected from an original group of 194 consecutively treated Chinese male patients who underwent Herbst appliance therapy at the Prince Philip Dental Hospital, Faculty of Dentistry, University of Hong Kong, from 1999 to 2010. In order to obtain a more homogeneous study sample, subjects were included only when the following criteria were fulfilled: at pretreatment (T0) (1) male aged between 11 and 16, (2) Wits appraisal with value greater than -1.5 (norm for Chinese: -4.5 , SD 3.0) [28], (3) angle Class II malocclusion (at least half-unit Class II molar relationship), (4) a convex facial profile, and (5) no permanent teeth extracted. Other criteria were as follows: (6) participants had undergone two-phase treatment with cast-type Herbst appliance, followed by preadjusted edgewise appliance, (7) the retention period between phase I and phase II did not exceed 3 months, (8) phase I should not be less than 9 months, but not more than 20 months, (9) phase II should not exceed 40 months, and (10) lateral cephalograms were obtained in natural head posture, with the teeth in centric occlusion and the lips in relaxed position [29] at pretreatment (T0), immediate post-Herbst (T1), and post-edgewise treatment (T2).

A sample of 30 male patients was available for further analysis (power $80 \% ; \alpha=0.05$ ). The age at the start of Herbst appliance therapy was $13.4 \pm 1.2$ years, with a range from 11.3 years to 15.9 years (Table 1). The total observation period was longer than the actual treatment time, as the pretreatment lateral cephalograms were taken, on average, three months before treatment. There was also a retention period of not exceeding three months between phase I and phase II.

The study sample was subdivided into three groups for further analysis according to the difference in the change in mandibular prognathism during the second phase: those with an increase of OLp-Pg more than $1.0 \mathrm{~mm}$ become the positive group; change of OLp-Pg within $1.0 \mathrm{~mm}$, the stable group; and with a decrease of OLp-Pg more than $1.0 \mathrm{~mm}$, the negative group.

2.2. Cephalometric Analysis. For calibration, 15 lateral cephalograms of 5 subjects were hand-traced initially by one investigator (RNYC) and verified by another investigator (UH). All lateral cephalograms were manually-traced by the same investigator (RNYC) twice, with one-week interval, and the two sets of data were then averaged in order to reduce the measurement error in landmark identification [30]. All the hand-tracings were then digitized and measured by the CASSOS software (CASSOS Clinical Evaluation Version 2004, Soft Enable Technology Limited, China). No corrections were made for linear radiographic enlargement (approximately 7\% in the median plane) [31].

The analysis of skeletal and dental changes was performed according to the method modified from Pancherz $[2,19]$. Template obtained from the first lateral cephalogram (T0) was superimposed on the subsequent lateral cephalograms using the structures of the anterior cranial base [32, 33] rather than on the nasion-sella line, as described originally by Pancherz $[2,19]$. Other parameters were also included to facilitate comparison with other studies: Wits appraisal, S-NA angle, S-N-B angle, A-N-B angle, the mandibular length (articulare to gnathion), the upper face height, lower face height, and the total face height (Figure 1).

2.3. Method Error Study. Prior to analysis, the treatment changes for 10 patients were assessed twice with a two-week interval to determine the method error. The magnitude of the combined method error (ME) in locating, superimposing, and measuring the changes of the different cephalometric landmarks was calculated by the Dahlberg's formula [34]: $\mathrm{ME}=\sqrt{\sum d^{2} / 2 n}$, where $d$ was the difference between the two measurements of a pair and $n$ was the number of double measurements. Paired $t$-test was also performed to assess systematic error. The combined error was not statistically significant and did not exceed \pm 0.4 ( $\mathrm{mm}$ or degree) for any of the variables investigated.

2.4. Statistical Analysis. Data analysis was performed with statistical analysis computer software (IBM SPSS Statistics 19.0.0, IBM Corporation, Route 100, Somers, NY 10589, US). The normality (Kolmogorov-Smirnov test) of the data 


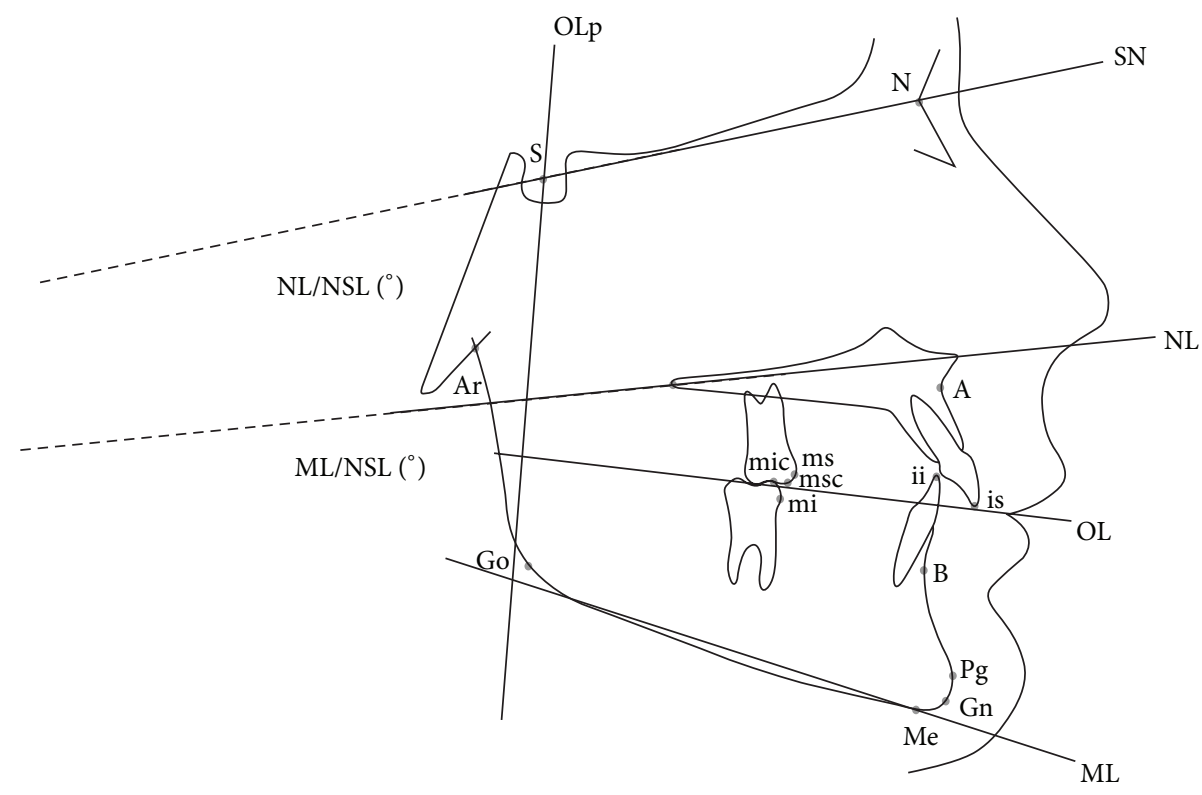

FIGURE 1: Cephalometric landmarks (for details please see $[2,19]$ ). Cephalometric reference lines are OL: maxillary occlusal plane, the line joining the distobuccal cusp tip of the maxillary permanent first molar and the upper incisor tip, is, and OLp: occlusal plane perpendicular to OL through S. Sagittal variables: overjet $(\mathrm{mm})$ : is-OLp minus ii-OLp; mandibular length ( $\mathrm{mm})$ : Ar-Gn; maxillary prognathism: A-OLp (mm) and S-N-A $\left(^{\circ}\right)$; mandibular prognathism: Pg-OLp $(\mathrm{mm})$ and S-N-B $\left(^{\circ}\right)$; jaw base relationship: A-Pg $(\mathrm{mm}), \mathrm{A}-\mathrm{N}-\mathrm{B}\left({ }^{\circ}\right)$, and A, B on functional occlusal plane $(\mathrm{mm})$; upper and lower incisor changes: is-A $(\mathrm{mm})$, is-OLp minus A-OLp and ii-Pg (mm), ii-OLp minus Pg-OLp; upper and lower first molar changes: ms-A (mm), ms-OLp minus A-OLp and mi-Pg (mm), mi-OLp minus Pg-OLp; and molar relationship: ms-mi $(\mathrm{mm})$, ms-OLp minus mi-OLp. Vertical variables: overbite $(\mathrm{mm})$ : ii-OL; upper face height $(\mathrm{mm})$ : N-NL; lower face height (mm): NL-Me; total face height (mm): NSL-Me; upper and lower incisor changes ( $\mathrm{mm}$ ): is-NL and ii-ML; upper and lower first molar changes (mm): $\mathrm{msc}-\mathrm{NL}$ and mic-ML. Rotational changes $\left({ }^{\circ}\right)$ : NSL/NL and NSL/ML.

appeared to be valid. The arithmetic mean (mean) and standard deviation (SD) for each variable were calculated. Independent $t$-test was carried out to compare the differences between groups. Paired $t$-test with Bonferroni correction and one-way ANOVA were used to examine the difference between the changes observed. Significance was set at $\alpha=$ 0.05 .

\section{Results}

3.1. Dentofacial Morphology of the Study Group (Table 2(a)) and the Subgroups (Table 2(b)). There were statistically significant differences in the dentofacial morphology between the study sample and the population norms $[28,35]$. The study sample presented with Class II jaw base relationships as indicated by the Wits appraisal, significant increase in A$\mathrm{Pg}$ and A-N-B angle; Class II molar relationship as indicated by the significant increase in $\mathrm{ms}-\mathrm{mi}$; significantly larger overjet, more prognathic maxilla in terms of OLp-A and more retrusive mandible in terms of S-N-B angle; increased upper face height; overerupted lower incisors relative to the mandibular plane; and overerupted maxillary molars relative to the maxillary plane.

When compared with the population norm, the positive group has a more prognathic maxilla (OLp-A) and normal mandible (OLp-Pg); the stable group has a relatively normal maxilla but more retrusive mandible, while the negative group has a more prognathic maxilla and more retrognathic mandible. The positive group has significant increase in overbite and decrease in mandibular plane angle (ML/NSL) when compared with the stable and negative groups and also the population norms, while the negative group has a significant increase in the upper face height (N-NL) when compared with the other two subgroups and the population norms.

3.2. Treatment Changes during the First Phase (T0-T1) Therapy with Cast-Herbst Appliance in the Study Group (Table 3(a)) and the Subgroups (Table 3(b)). The statistically significant treatment changes during phase I were the decrease in overjet and overbite, increased maxillary prognathism (OLpA), mandibular prognathism (OLp-Pg and S-N-B angle), mandibular growth (Ar-Gn) and upper and lower face heights (N-NL and NSL-Me), improvement in jaw base (Wits appraisal, A-Pg, and A-N-B angle) and molar relationships, protrusion of lower incisors, and eruption of lower molars. About $50 \%$ of overjet correction was due to the change in skeletal base (Figure 2(a)); skeletal effect contributed less $(42.5 \%)$ than dentoalveolar effect $(57.5 \%)$ in the correction of molar relationship (Figure 3(a)). No significant differences were observed among the three subgroups during the first phase treatment.

3.3. Treatment Changes during the Second Phase (T1-T2) Therapy with Preadjusted Edgewise Appliance in the Study Group (Table 3(a)) and the Subgroups (Table 3(b)). During phase II, the statistically significant effects observed were 
TABLE 2: (a) Comparison of dentofacial morphology between the population normand the study sample at the start of treatment (T0) and after phase I (T1) and phase II (T2) treatment. (b) Comparison of dentofacial morphology with the population norm and the three subgroups at the start of treatment (T0).

(a)

\begin{tabular}{|c|c|c|c|c|c|c|c|c|}
\hline \multirow{2}{*}{ Variables } & \multicolumn{2}{|c|}{ Population norm } & \multicolumn{2}{|c|}{ T0 } & \multicolumn{2}{|c|}{$\mathrm{T} 1$} & \multicolumn{2}{|c|}{$\mathrm{T} 2$} \\
\hline & Mean & SD & Mean & $\mathrm{SD}$ & Mean & SD & Mean & SD \\
\hline \multicolumn{9}{|l|}{ Sagittal } \\
\hline Overjet (mm) & 4.3 & 1.76 & $9.8^{* * *}$ & 3.13 & $0.6^{* * *}$ & 2.91 & 3.9 & 0.88 \\
\hline Wits appraisal (mm) & -4.5 & 3.00 & $3.6^{* * *}$ & 3.58 & -4.3 & 3.34 & $0.2^{* * *}$ & 3.06 \\
\hline \multicolumn{9}{|l|}{ Maxillary prognathism } \\
\hline OLp-A (mm) & 76.1 & 3.86 & $80.2^{* *}$ & 4.25 & $82.4^{* * *}$ & 4.22 & $83.1^{* * *}$ & 4.25 \\
\hline S-N-A $\left({ }^{\circ}\right)$ & 82.0 & 3.50 & 82.6 & 3.69 & 83.1 & 3.36 & 82.4 & 3.12 \\
\hline \multicolumn{9}{|c|}{ Mandibular prognathism } \\
\hline OLp-Pg (mm) & 82.3 & 4.88 & $79.2^{* *}$ & 6.74 & $86.0^{* * *}$ & 8.30 & $86.4^{* * *}$ & 8.99 \\
\hline OLp-B (mm) & N/A & N/A & 77.0 & 5.93 & 83.6 & 7.34 & 83.4 & 7.66 \\
\hline Ar-Gn & N/A & N/A & 104.0 & 5.78 & 112.0 & 6.88 & 113.9 & 7.73 \\
\hline $\mathrm{S}-\mathrm{N}-\mathrm{B}\left(^{\circ}\right)$ & 79.0 & 3.00 & $75.1^{* * *}$ & 3.45 & $77.7^{*}$ & 3.93 & $77.1^{* *}$ & 4.31 \\
\hline \multicolumn{9}{|l|}{ Jaw base relationship } \\
\hline $\mathrm{A}-\mathrm{Pg}(\mathrm{mm})$ & -6.2 & 3.38 & $1.1^{* * *}$ & 3.76 & $-3.5^{* * *}$ & 5.53 & $-3.3^{* * *}$ & 5.99 \\
\hline A-N-B $\left(^{\circ}\right)$ & 3.0 & 2.00 & $7.5^{* * *}$ & 1.78 & $5.4^{* * *}$ & 1.93 & $5.3^{* * *}$ & 2.20 \\
\hline \multicolumn{9}{|l|}{ Maxillary incisor } \\
\hline OLp-is (mm) & 88.1 & 4.54 & 91.8 & 4.89 & $93.0^{* * *}$ & 5.30 & $93.7^{* * *}$ & 5.40 \\
\hline \multicolumn{9}{|l|}{ Mandibular incisor } \\
\hline OLp-ii (mm) & 83.8 & 4.44 & 82.0 & 4.75 & $92.4^{* * *}$ & 5.79 & $89.7^{* * *}$ & 5.13 \\
\hline \multicolumn{9}{|l|}{ Maxillary molar } \\
\hline OLp-ms (mm) & 55.0 & 3.98 & 56.7 & 4.30 & 56.0 & 5.07 & $60.6^{* * *}$ & 5.30 \\
\hline \multicolumn{9}{|l|}{ Mandibular molar } \\
\hline OLp-mi (mm) & 57.7 & 4.26 & 54.6 & 4.95 & $64.6^{* * *}$ & 6.02 & $64.0^{* * *}$ & 5.88 \\
\hline \multicolumn{9}{|l|}{ Molar relationship } \\
\hline ms-mi (mm) & -2.7 & 1.62 & $2.1^{* * *}$ & 1.77 & $-8.6^{* * *}$ & 2.33 & $-3.4^{*}$ & 2.04 \\
\hline \multicolumn{9}{|l|}{ Vertical } \\
\hline Overbite (mm) & 2.2 & 1.51 & 3.2 & 2.60 & $-0.1^{* * *}$ & 1.44 & 1.0 & 0.89 \\
\hline \multicolumn{9}{|l|}{ Upper face height } \\
\hline $\mathrm{N}-\mathrm{NL}(\mathrm{mm})$ & 54.0 & 3.50 & $57.2^{* * *}$ & 3.48 & $59.7^{* * *}$ & 3.89 & $60.7^{* * *}$ & 3.55 \\
\hline \multicolumn{9}{|l|}{ Lower face height } \\
\hline $\mathrm{NL}-\mathrm{Me}(\mathrm{mm})$ & 64.0 & 4.00 & 65.5 & 4.54 & $71.0^{* * *}$ & 5.34 & $72.7^{* * *}$ & 5.52 \\
\hline \multicolumn{9}{|l|}{ Total face height } \\
\hline NSL-Me (mm) & N/A & N/A & 117.8 & 6.50 & 126.4 & 7.23 & 129.0 & 7.16 \\
\hline \multicolumn{9}{|l|}{ Incisor position } \\
\hline is- $\mathrm{NL}(\mathrm{mm})$ & 28.9 & 2.72 & 30.5 & 2.82 & $32.9^{* * *}$ & 2.98 & $33.7^{* * *}$ & 3.14 \\
\hline ii-ML (mm) & 41.3 & 2.73 & $43.9^{* *}$ & 3.35 & $43.4^{* *}$ & 3.68 & $44.8^{* * *}$ & 3.72 \\
\hline \multicolumn{9}{|l|}{ Molar position } \\
\hline msc-NL (mm) & 21.9 & 2.22 & $23.7^{*}$ & 2.25 & 23.1 & 2.74 & $26.0^{* * *}$ & 3.03 \\
\hline mic-ML (mm) & 31.8 & 2.41 & 33.2 & 2.25 & $35.9^{* * *}$ & 2.54 & $37.8^{* * *}$ & 3.09 \\
\hline \multicolumn{9}{|l|}{ Rotational changes } \\
\hline NL/NSL $\left({ }^{\circ}\right)$ & 9.1 & 3.34 & 9.8 & 2.46 & 9.8 & 3.00 & 9.4 & 3.26 \\
\hline ML/NSL $\left({ }^{\circ}\right)$ & 35.3 & 5.57 & 34.8 & 7.28 & 34.0 & 7.49 & 33.6 & 8.38 \\
\hline
\end{tabular}

SD: Standard deviation.

${ }^{*} P<0.05,{ }^{* *} P<0.01,{ }^{* * *} P<0.001$.

(b)

\begin{tabular}{|c|c|c|c|c|c|c|c|c|}
\hline \multirow{2}{*}{ Variables } & \multicolumn{2}{|c|}{ Population norm } & \multicolumn{2}{|c|}{ Positive group } & \multicolumn{2}{|c|}{ Stable group } & \multicolumn{2}{|c|}{ Negative group } \\
\hline & Mean & $\mathrm{SD}$ & Mean & $\mathrm{SD}$ & Mean & $\mathrm{SD}$ & Mean & $\mathrm{SD}$ \\
\hline \multicolumn{9}{|l|}{ Sagittal } \\
\hline Overjet (mm) & 4.3 & 1.76 & $10.3^{* * *}$ & 2.54 & $8.6^{* * *}$ & 3.45 & $10.3^{* * *}$ & 3.34 \\
\hline Wits appraisal $(\mathrm{mm})$ & -4.5 & 3.00 & $3.7^{* * *}$ & 2.60 & $3.4^{* * *}$ & 2.85 & $3.7^{* * *}$ & 5.13 \\
\hline \multicolumn{9}{|l|}{ Maxillary prognathism } \\
\hline OLp-A (mm) & 76.1 & 3.86 & $80.6^{* * *}$ & 3.90 & 78.2 & 4.30 & $81.9^{* * *}$ & 4.04 \\
\hline $\operatorname{SNA}\left({ }^{\circ}\right)$ & 82.0 & 3.50 & 83.3 & 3.87 & 81.4 & 3.45 & 83.0 & 3.83 \\
\hline
\end{tabular}


(b) Continued.

\begin{tabular}{|c|c|c|c|c|c|c|c|c|}
\hline \multirow{2}{*}{ Variables } & \multicolumn{2}{|c|}{ Population norm } & \multicolumn{2}{|c|}{ Positive group } & \multicolumn{2}{|c|}{ Stable group } & \multicolumn{2}{|c|}{ Negative group } \\
\hline & Mean & $\mathrm{SD}$ & Mean & SD & Mean & $\mathrm{SD}$ & Mean & $\mathrm{SD}$ \\
\hline \multicolumn{9}{|c|}{ Mandibular prognathism } \\
\hline OLp-Pg $(\mathrm{mm})$ & 82.3 & 4.88 & 81.0 & 5.65 & $77.5^{* *}$ & 8.04 & $79.0^{*}$ & 6.54 \\
\hline OLp-B (mm) & N/A & N/A & 78.2 & 5.54 & 75.3 & 7.10 & 77.5 & 5.21 \\
\hline Ar-Gn & $\mathrm{N} / \mathrm{A}$ & $\mathrm{N} / \mathrm{A}$ & 104.9 & 6.08 & 101.8 & 5.07 & 105.4 & 6.05 \\
\hline $\operatorname{SNB}\left({ }^{\circ}\right)$ & 79.0 & 3.00 & $76.4^{* * *}$ & 4.26 & $74.2^{* * *}$ & 3.07 & $74.7^{* * *}$ & 2.83 \\
\hline \multicolumn{9}{|c|}{ Jaw base relationship } \\
\hline A-Pg $(\mathrm{mm})$ & -6.2 & 3.38 & $-0.4^{* * *}$ & 2.98 & $0.7^{* * *}$ & 4.40 & $2.9^{* * *}$ & 3.35 \\
\hline ANB $\left(^{\circ}\right)$ & 3.0 & 2.00 & $6.9^{* * *}$ & 2.03 & $7.2^{* * *}$ & 1.50 & $8.3^{* * *}$ & 1.65 \\
\hline \multicolumn{9}{|l|}{ Maxillary incisor } \\
\hline OLp-is (mm) & 88.1 & 4.54 & $92.6^{* * *}$ & 4.64 & 88.6 & 3.64 & $94.2^{* * *}$ & 4.89 \\
\hline \multicolumn{9}{|l|}{ Mandibular incisor } \\
\hline OLp-ii (mm) & 83.8 & 4.44 & 82.3 & 4.59 & 80.0 & 4.51 & 83.9 & 4.80 \\
\hline \multicolumn{9}{|l|}{ Maxillary molar } \\
\hline OLp-ms (mm) & 55.0 & 3.98 & 56.4 & 4.53 & 56.0 & 4.68 & 57.7 & 3.93 \\
\hline \multicolumn{9}{|l|}{ Mandibular molar } \\
\hline OLp-mi (mm) & 57.7 & 4.26 & 54.2 & 5.01 & 53.6 & 5.44 & 56.1 & 4.51 \\
\hline \multicolumn{9}{|c|}{ Molar relationship (mm) } \\
\hline ms-mi (mm) & -2.7 & 1.62 & $2.1^{* * *}$ & 1.81 & $2.4^{* * *}$ & 1.70 & $1.6^{* * *}$ & 1.88 \\
\hline \multicolumn{9}{|l|}{ Vertical } \\
\hline Overbite (mm) & 2.2 & 1.51 & $4.4^{* * *}$ & 1.61 & 2.9 & 2.93 & 2.2 & 2.76 \\
\hline \multicolumn{9}{|l|}{ Upper face height } \\
\hline N-NL (mm) & 54.0 & 3.50 & 56.4 & 2.68 & 56.0 & 2.27 & $59.2^{* * *}$ & 4.48 \\
\hline \multicolumn{9}{|l|}{ Lower face height } \\
\hline $\mathrm{NL}-\mathrm{Me}(\mathrm{mm})$ & 64.0 & 4.00 & 64.3 & 4.07 & 64.1 & 2.70 & 68.0 & 5.63 \\
\hline \multicolumn{9}{|l|}{ Total face height } \\
\hline NSL-Me (mm) & $\mathrm{N} / \mathrm{A}$ & $\mathrm{N} / \mathrm{A}$ & 116.6 & 5.17 & 114.7 & 4.52 & 122.2 & 7.40 \\
\hline \multicolumn{9}{|l|}{ Incisor position } \\
\hline is- $\mathrm{NL}(\mathrm{mm})$ & 28.9 & 2.72 & 30.3 & 2.84 & 30.0 & 2.48 & $31.1^{*}$ & 3.27 \\
\hline ii-ML (mm) & 41.3 & 2.73 & $43.5^{*}$ & 2.21 & 42.3 & 1.72 & $45.9^{* * *}$ & 4.56 \\
\hline \multicolumn{9}{|l|}{ Molar position } \\
\hline msc-NL (mm) & 21.9 & 2.22 & $23.5^{*}$ & 2.38 & $23.6^{*}$ & 1.96 & $23.9^{* *}$ & 2.59 \\
\hline mic-ML (mm) & 31.8 & 2.41 & 32.8 & 2.22 & 32.8 & 1.98 & $34.1^{* *}$ & 2.51 \\
\hline \multicolumn{9}{|l|}{ Rotational changes } \\
\hline NL/NSL $\left(^{\circ}\right)$ & 9.1 & 3.34 & 8.8 & 2.04 & $11.3^{*}$ & 2.46 & 9.4 & 2.33 \\
\hline ML/NSL $\left(^{\circ}\right)$ & 35.3 & 5.57 & $31.1^{*}$ & 8.11 & 35.1 & 6.40 & 38.1 & 6.00 \\
\hline
\end{tabular}

SD: Standard deviation.

${ }^{*} P<0.05,{ }^{* *} P<0.01,{ }^{* * *} P<0.001$.

rebound in overjet and overbite, further increase in maxillary prognathism and mandibular growth, retroclination of lower incisors, mesialization of maxillary molars, deterioration of the molar relationship, further increase in the upper and lower face heights, and eruption of upper and lower incisors and molars (Figures 2(a) and 3(a)). During this phase, onethird of the patients continued to have forward positioning of the mandible (positive group) (Figures 2(b) and 3(b)). Onethird remained relatively unchanged (stable group) (Figures $2(\mathrm{c})$ and $3(\mathrm{c})$ ), while the remaining one-third showed a decrease in mandibular prognathism (negative group) (Figures 2(d) and 3(d)). Apart from forward positioning of the mandible, the positive group has a more significant increase in mandibular length, improvement in jaw base relationship, more retroclined lower incisors, and smaller mandibular plane angle when compared with the stable and negative groups.

3.4. Treatment Changes of the Overall Treatment Period (T0T2) in the Study Sample (Table 3(a)) and the Subgroups (Table 3(b)). The statistically significant treatment changes observed for the combined phases were improvement in overjet and overbite, increase in maxillary and mandibular prognathism, increase in upper and lower face heights, enhanced mandibular growth, improvement in jaw base relationship, mesialization of mandibular molars, and eruption of upper and lower molars. For the total treatment period, $71.2 \%$ of overjet reduction was contributed by skeletal effect; dentoalveolar changes played a less significant role (Figure 2(a)). The same is also true for the improvement in 


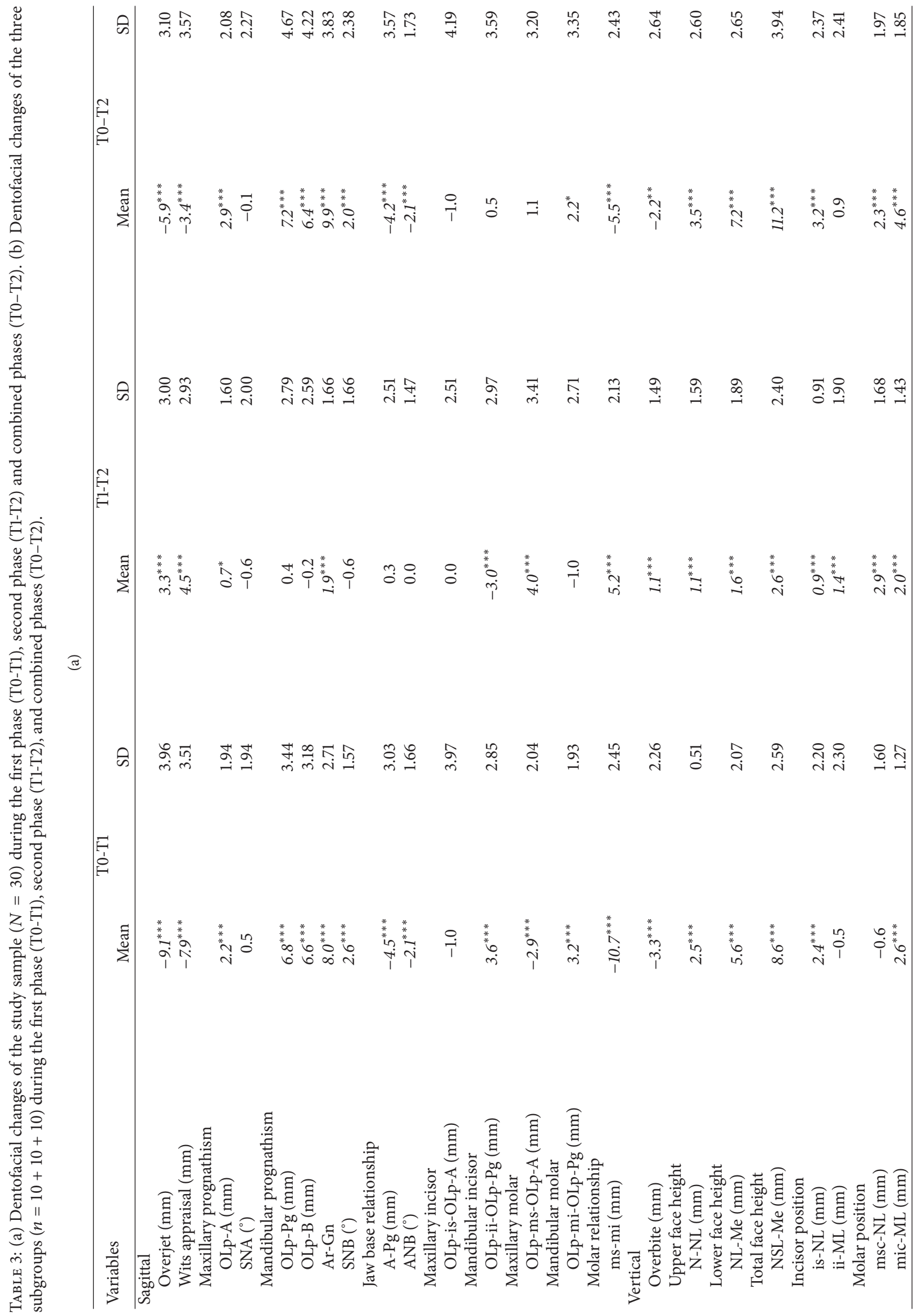




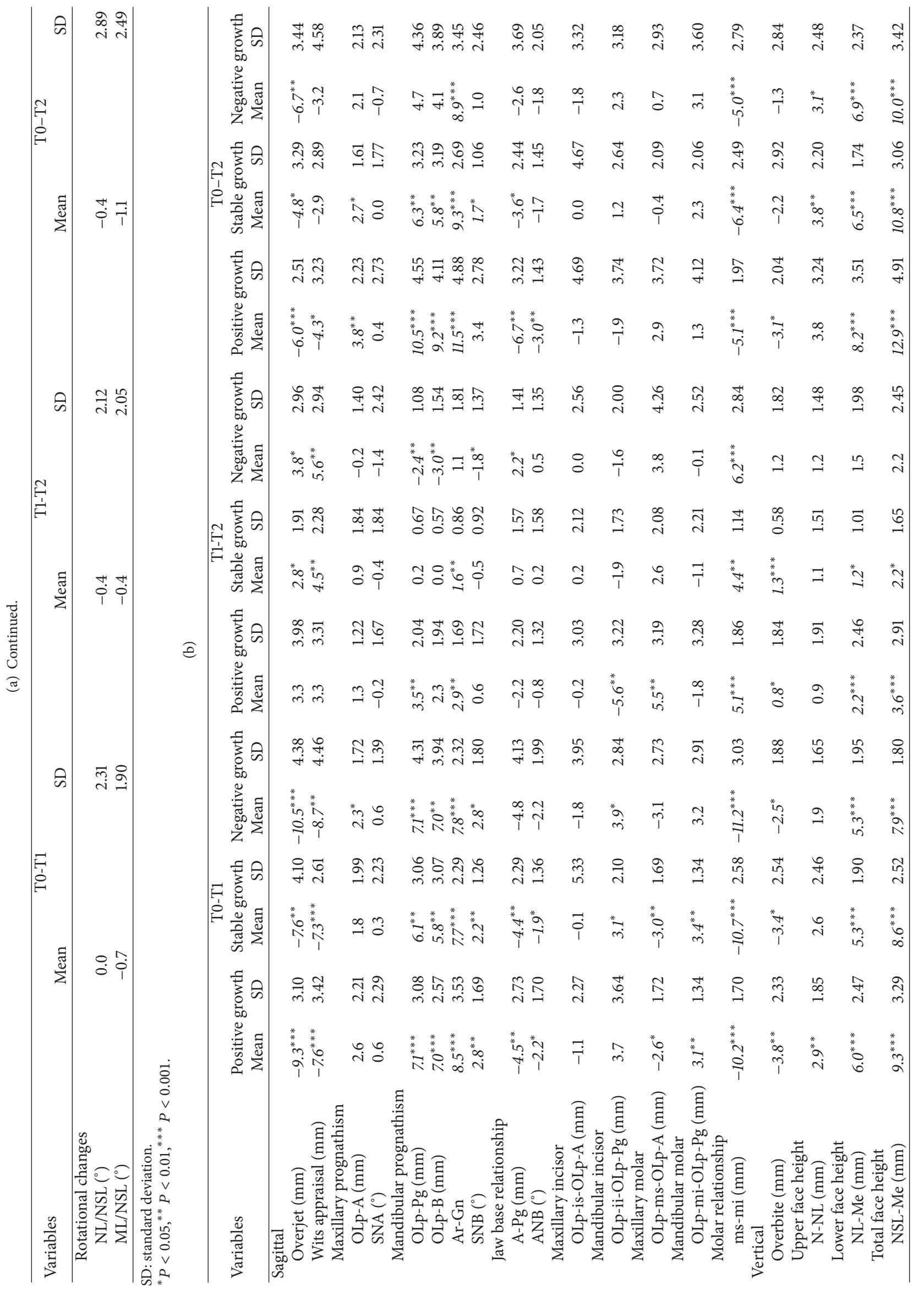




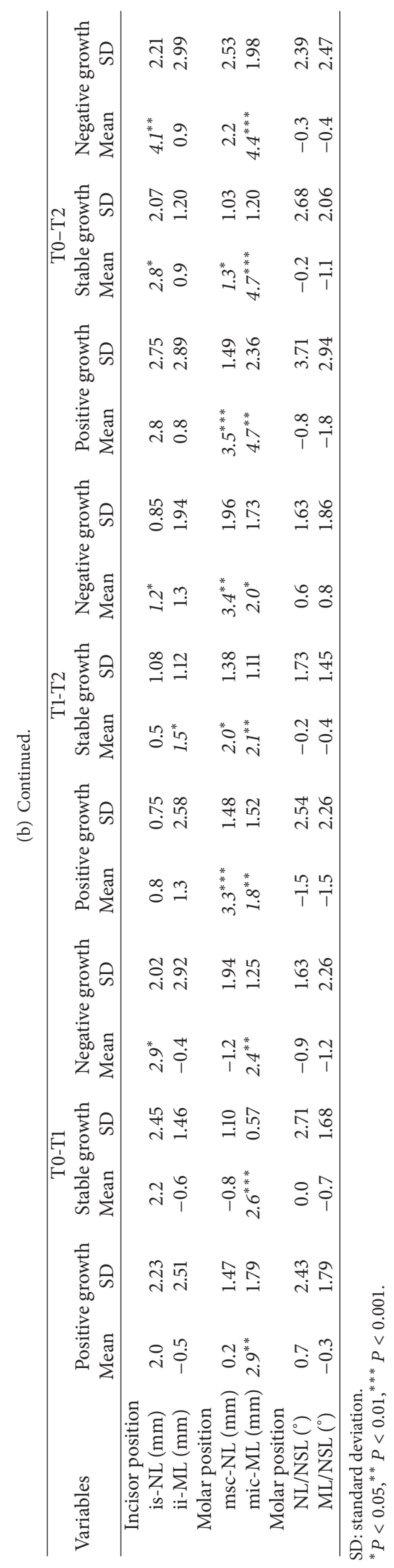


molar relationship. Skeletal change contributed 78.2\%, while dentoalveolar effects only contributed $21.8 \%$ in its overall correction (Figure 3(a)).

For the positive group, improvements in overjet and molar relationship were completely due to skeletal changes (Figures 2(b) and 3(b)). Skeletal effects contributed about 75\% to overjet reduction in the stable group; only $25 \%$ was due to dentoalveolar effects (Figure 2(c)). For the correction of molar relationship, about $57 \%$ was due to skeletal effects, $43 \%$ was contributed by dentoalveolar changes (Figure 3(c)). For the negative group, dentoalveolar effects were more dominant in the overjet correction (about $40 \%$ skeletal and $60 \%$ dental) (Figure 2(d)), while skeletal and dentoalveolar effects played equal parts in the improvement in the molar relationship (Figure 3(d)).

\section{Discussion}

In this retrospective clinical study, strict inclusion criteria were adopted in order to obtain a more homogenous study sample that presented with skeletal Class II for evaluation. Linear cephalometric measurements are known to be more accurate and reliable than angular measurements $[36,37]$. Angular measurements, such as A-N-B angle, are not valid for assessment of changes in the jaw base position during growth because reduction in A-N-B angle could have occurred, for instance, as a result of differential growth between the nasion and the A-point. Such change might exaggerate the restraint of maxillary prognathism and mask the increase of mandibular prognathism. Therefore, Wits appraisal, together with the molar relationship, was used to identify patients with skeletal Class II instead. For evaluation of treatment changes, a method modified from Pancherz $[2,19]$ was used. Increased overjet was not used to identify skeletal Class II because large overjet more than one or even two standard deviations (SD) to the population norms did not necessarily mean that the subjects have Class II jaw base relationship [38]. In fact, in one RCT study that used increased overjet as an inclusion criterion [13], the A-N-B angle of the sample ranged from $0.4(-1 \mathrm{SD})$ to $12.2(+4 \mathrm{SD})$ degrees, indicating that the sample was comprised of malocclusions ranging from mild skeletal Class III to very severe skeletal Class II.

Cast-Herbst appliance was chosen in the present study since it is particularly advantageous over other removable appliances as it works round the clock, and patient compliance is not an issue. Operators had experience handling the appliance, and laboratory technicians had fabricated the appliance for many years. Less breakage was observed than the banded type of Herbst. Even though more debond has been encountered with the cast-Herbst, the management is much easier [39].

Usually patients treated with Herbst appliance are more dentally mature, as anchorage requires fully erupted first premolars [40]. It was also recommended that, to take advantage of the increase in condylar growth and to reduce posttreatment retention time, Herbst therapy should be carried out close to the pubertal maximum of growth [41] to enhance the skeletal effects. There is only a small sex difference in the eruption of the first premolars, whereas the difference in the occurrence of the pubertal growth spurt differs 2 years [42]. In most RCT studies, data for the males and females were pooled despite the sex difference in the timing of puberty and the magnitude of growth. It was recommended that sexes should be analyzed separately especially in adolescence [41]. Therefore, only male patients who aged between 11 and 16 were included in this study, since they will not have passed their pubertal maximum before their first premolars have erupted and functional appliance therapy started, whereas many females might have passed their pubertal maximum before the specific anchorage teeth have erupted [42].

It was recommended by Herbst [43] that treatment duration with his appliance should not be less than 9 months, and an experimental study also suggested that sufficient time after forward positioning with a fixed jumping device was necessary to allow the newly formed condylar bone to mature and become stable, thus enabling normal growth to be maintained afterwards [44].

The study sample had Class II jaw base and molar relationships. They have significantly more prognathic maxilla and more retrusive mandible when compared with the population norms $[28,35]$. This is in general agreement with another study on the dentofacial morphology on Chinese subjects with Class II malocclusion [45].

Significant improvement in overjet and overbite was observed after Herbst appliance therapy in 100\% of the study sample, with protrusion of lower incisor and eruption of lower molars. Normalization of the jaw base and molar relationships was accomplished by significant forward positioning of the mandible and increase in mandibular length, distalization of upper molars, and mesialization of lower molars. The average increase in forward positioning of the mandible was $6.8 \mathrm{~mm}$ in 13 months, which is more than twice of that of normal growth [46] and indicated that there is an enhancement effect on mandibular prognathism with the Herbst appliance. The changes observed were in general agreement with the previous studies $[3,5,25,27,40]$. However, significant increase in the upper and lower face heights was also observed, which is in contrast with some of the studies [21, 27, 47].

After the Herbst appliance treatment in phase I, mandibular prognathism increased in $100 \%$ of the patients, but during phase II, only one-third of the patients continued to have forward positioning of the mandible. In one-third of the patients the mandible remained relatively unchanged, while in the remaining one-third the mandibular prognathism decreased (Figure 3(a)). However, significant increase in mandibular length was still observed in $100 \%$ of the patients in phase II. Such findings indicated that, instead of "subnormal" growth in the post-Herbst period, the mandible continued to grow in the stable and negative groups, but mainly vertically rather than sagittally.

For the positive group, the overall (T0-T2) improvements in overjet and molar relationship were completely due to skeletal changes (Figures 2(b) and 3(b)). In the negative group dentoalveolar effects were more dominant in overjet correction (Figure 2(d)), while skeletal and dentoalveolar effects 
(i) Phase I (T0-T1)

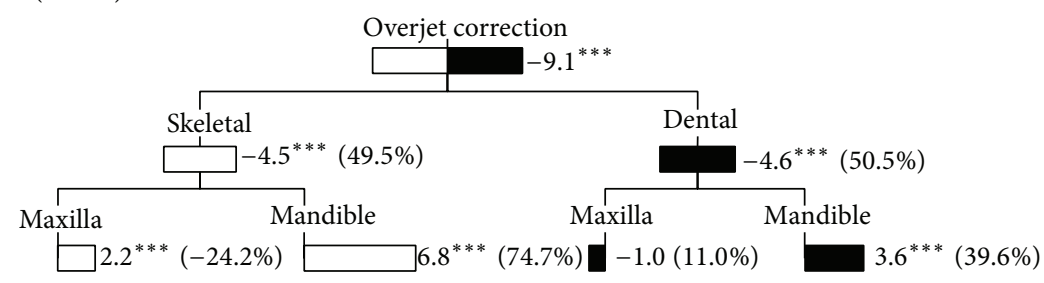

(ii) Phase II (T1-T2)

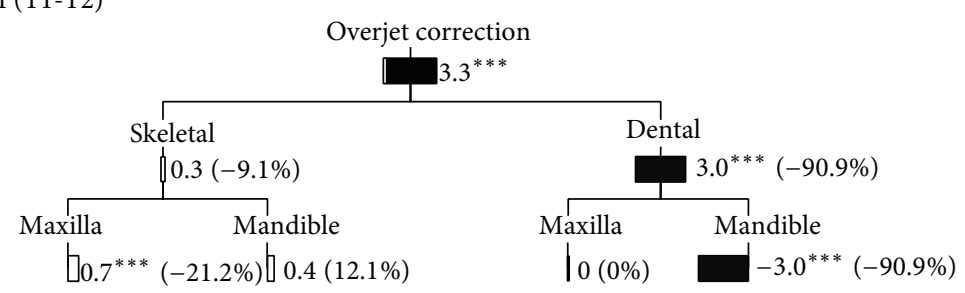

(iii) Combined phase (T0-T2)

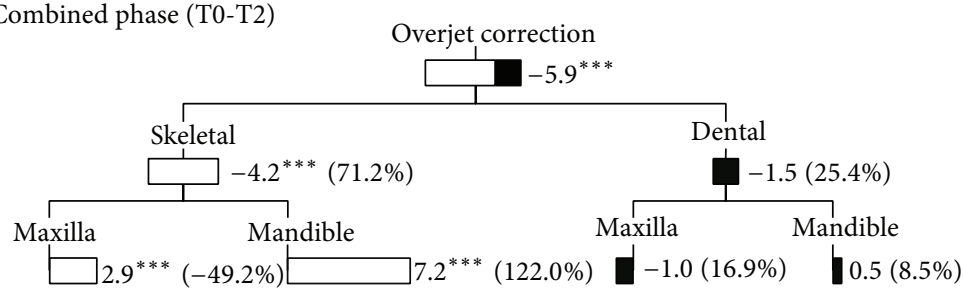

(a)

(i) Phase I (positive group)

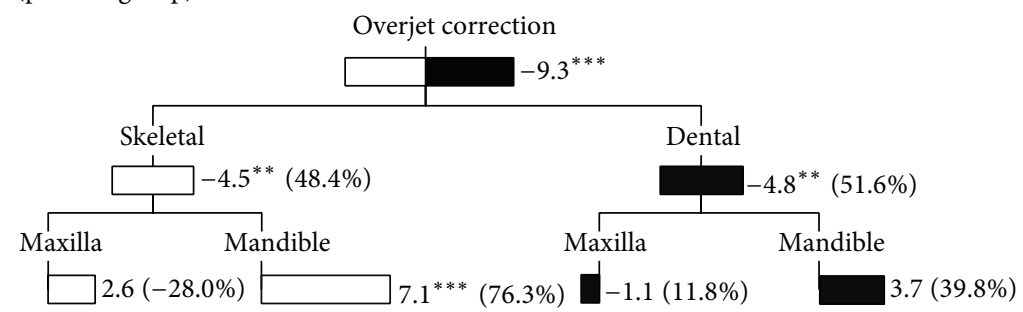

(ii) Phase II (positive group)

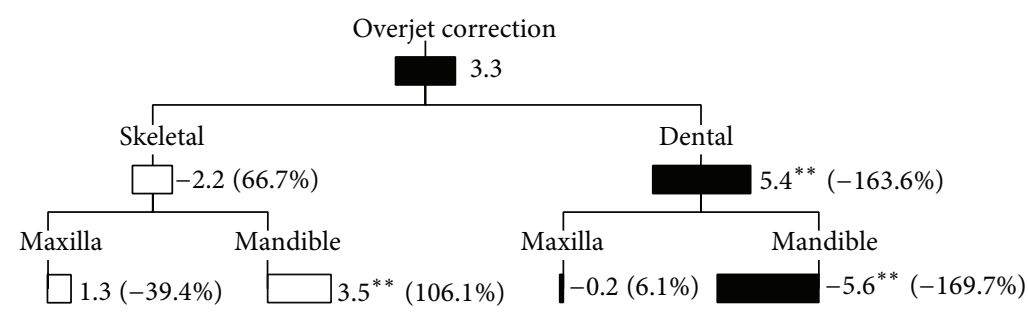

(iii) Combined phase (positive group)

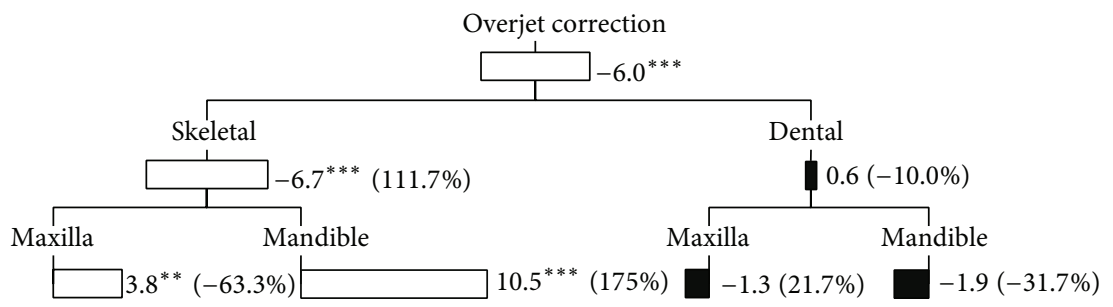

(b)

Figure 2: Continued. 
(i) Phase I (stable group) Overjet correction

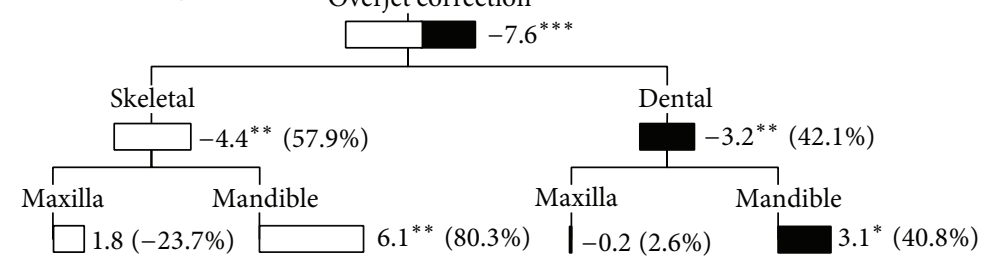

(ii) Phase II (stable group)

Overjet correction

$\square 2.8^{*}$

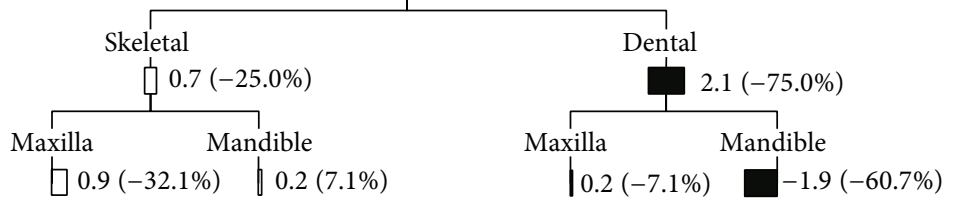

(iii) Combined phase (stable group)

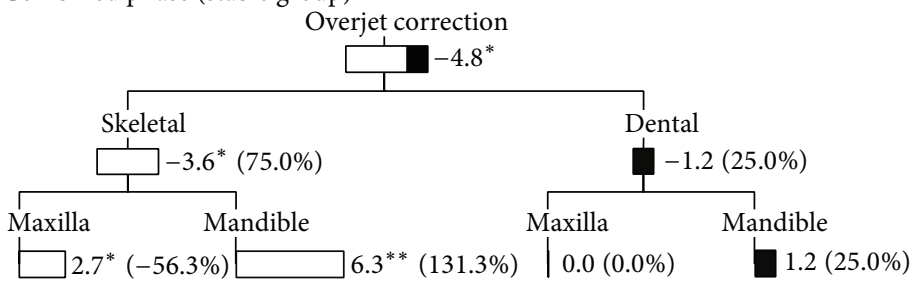

(c)

(i) Phase I (negative group) Overjet correction

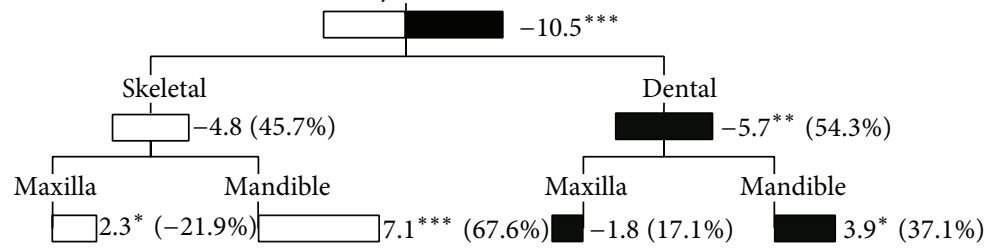

(ii) Phase II (negative group)

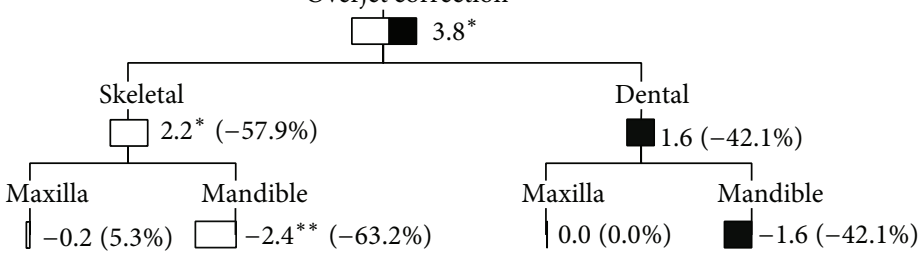

(iii) Combined phase (negative group)

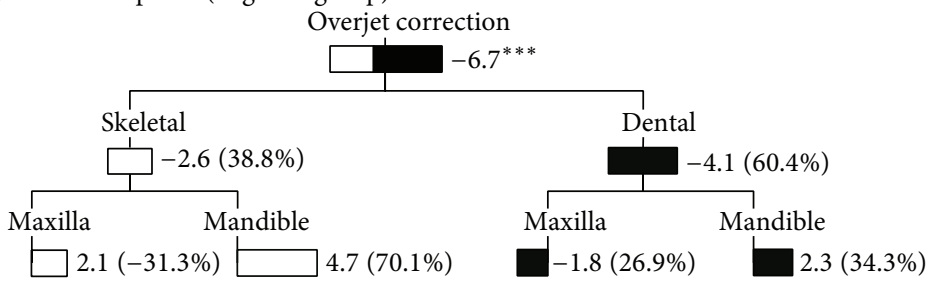

(d)

FIGURE 2: Overjet correction of (a) the whole study sample, (b) positive group, (c) stable group, and (d) negative group for phase I (T0-T1), phase II (T1-T2), and the total treatment period (T0-T2) $\left({ }^{*} P<0.05 ;{ }^{* *} P<0.01 ;{ }^{* * *} P<0.001\right)$. 


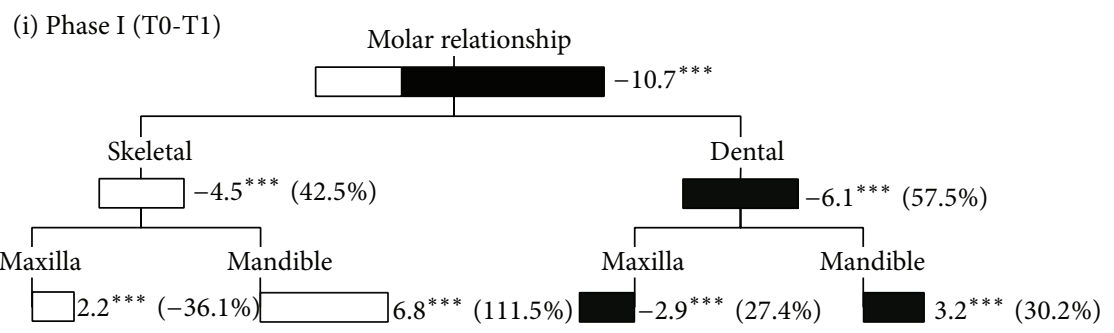

(ii) Phase II (T1-T2) Molar relationship

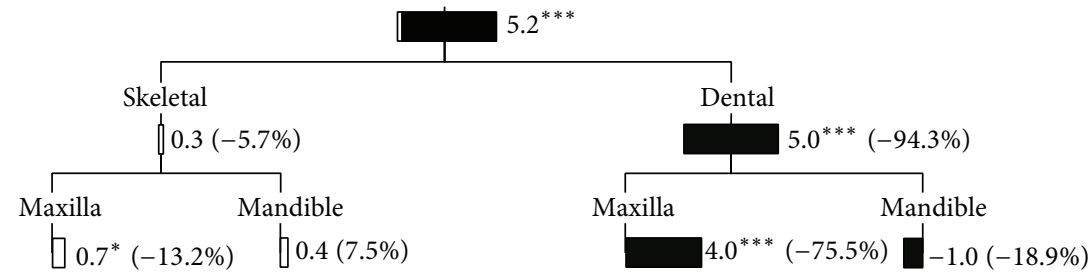

(iii) Combined phase (T0-T2) Molar relationship

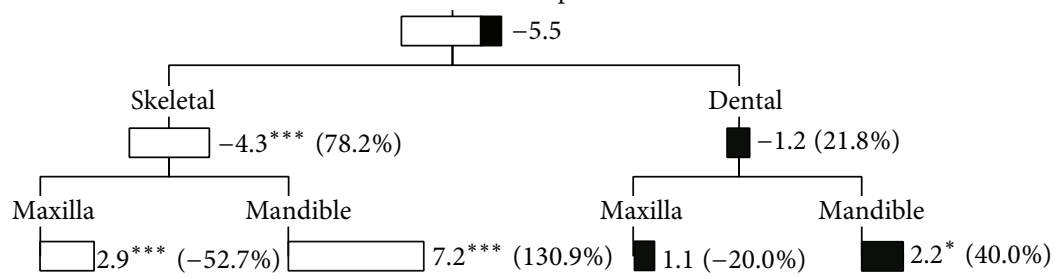

(a)

(i) Phase I (positive group)

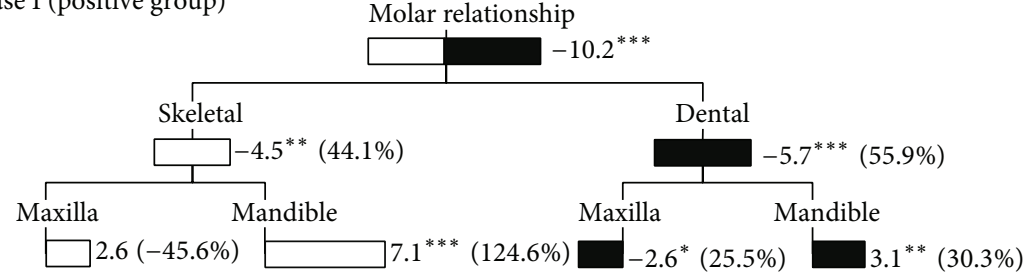

(ii) Phase II (positive group)

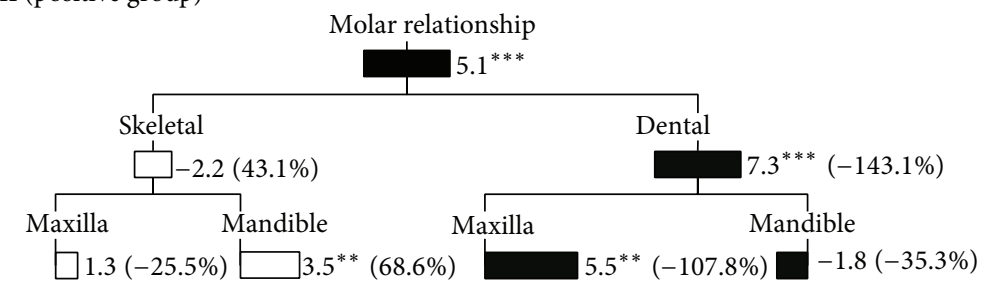

(iii) Combined phase (positive group)

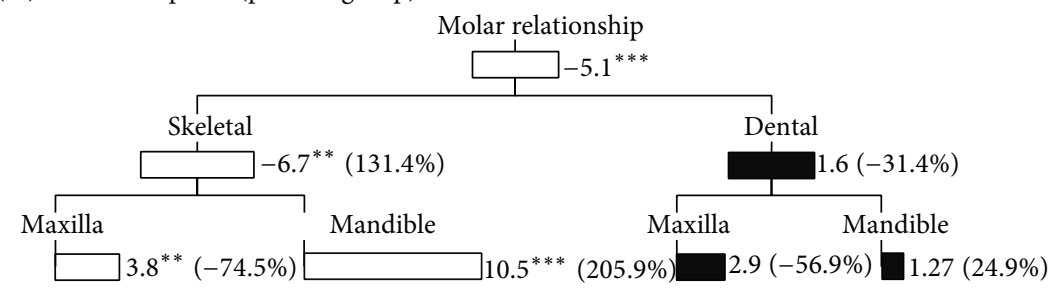

(b)

Figure 3: Continued. 


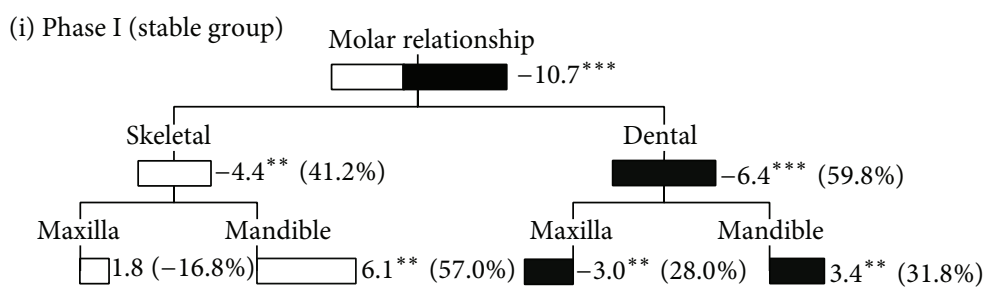

(ii) Phase II (stable group) Molar relationship

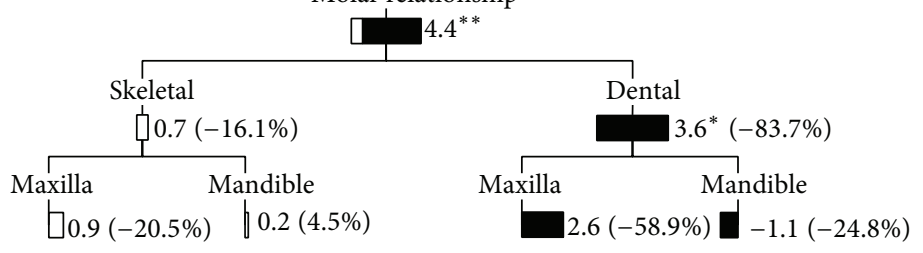

(iii) Combined phase (stable group)

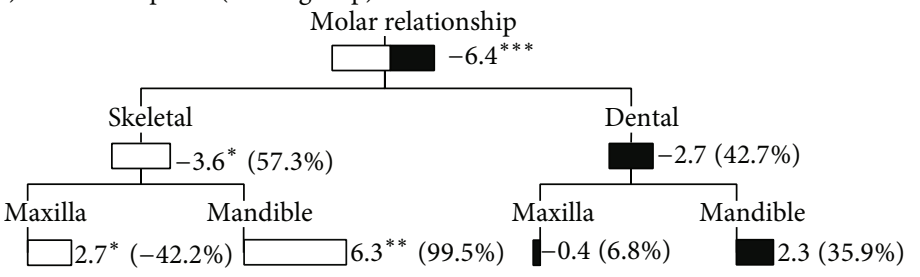

(c)

(i) Phase I (negative group)

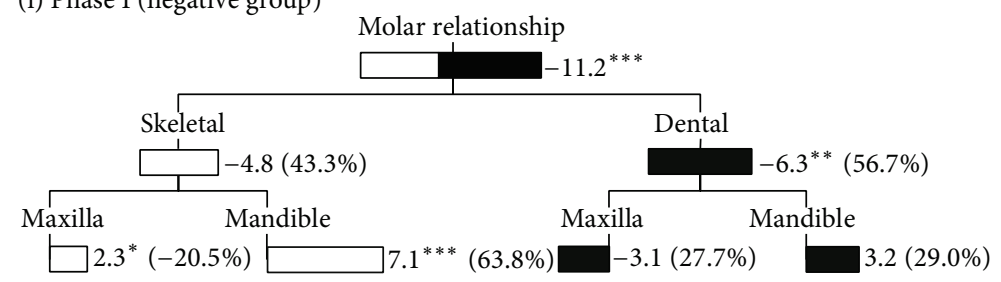

(ii) Phase II (negative group)

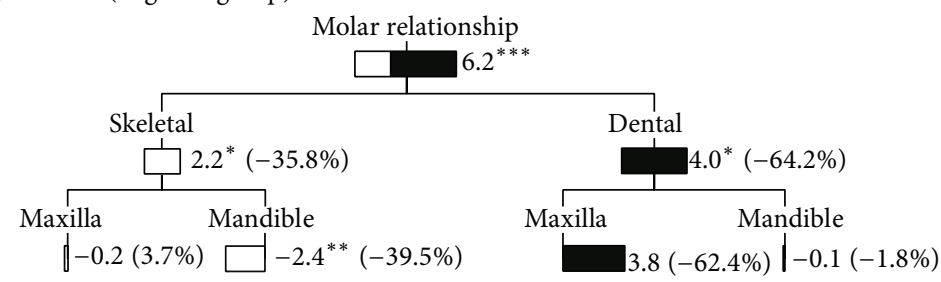

(iii) Combined phase (negative group)

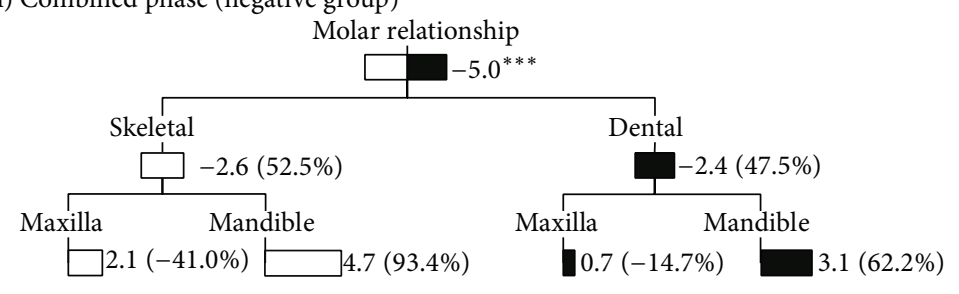

(d)

FIGURE 3: Molar correction of (a) the whole study sample, (b) positive growth group, (c) stable growth group, and (d) negative growth group for phase I (T0-T1), phase II (T1-T2), and the total treatment period (T0-T2) in the positive growth group $\left({ }^{*} P<0.05 ;{ }^{* *} P<0.01\right.$; $\left.{ }^{* * *} P<0.001\right)$. 
played equal parts in the normalization of molar relationship (Figure 3(d)). Moreover, during phase II, the lower incisors were significantly more retroclined in the positive group compared with the other two groups. Therefore, a good vertical control of the maxilla and sagittal control of the incisor inclination may be beneficial to the correction of skeletal Class II malocclusion.

For the total treatment period (T0-T2), there were significant improvement in the study sample in overjet and overbite, with normalization of the jaw base and molar relationships, and increase in upper and lower face heights. During phase I, skeletal changes contributed $49.5 \%$ and $42.5 \%$ to the overjet and molar corrections, respectively, whereas at the end of phase II, due to dentoalveolar relapse, contributions from skeletal changes increased to $71.2 \%$ and $78.2 \%$, respectively (Figures $2(\mathrm{a})$ and $3(\mathrm{a})$ ). Such findings were in conflict with some of the previous studies, which concluded that functional appliance treatment does not have beneficial clinical effect in the correction of skeletal Class II malocclusion [11, 13, 48]. The differences in treatment changes in the three subgroups demonstrated clearly the large variation in treatment response with the same orthodontic appliance, which might reflect that the underlying growth pattern differs between groups, and also reflect the weakness of current diagnostic methods. However, as stated before, due to the shortcomings of RCTs in evaluating the orthodontic treatment outcomes, conclusions valid in the clinical context still could not be drawn.

The limitations of the present study are the small sample size and no comparable control group. The small sample size obtained under the specific inclusion criteria did not allow us to investigate if there were differences in the treatment changes between patients who were treated with headgearHerbst or Herbst only, maximum or stepwise advancement of the bite during the Herbst treatment, or extraction and nonextraction therapy. However, these different modes of treatment were found in all three subcategories, so there was no obvious bias in this context.

Ideally, it had been desirable with a matched control group, but it is neither practical nor ethical to leave a group of growing patients seeking treatment untreated for a longer period of time. In fact none of the RCTs has a control group for the whole two-phase treatment. If they had a control group, it was for the first phase only [14].

Future studies have to be planned with great skills and caution, in attempt to minimize the unavoidable flaws. Meanwhile, those colleagues who use functional appliances on selected cases and in a skilled manner seem to have no sound scientific reason not to continue to do so.

\section{Conclusions}

(1) During phases I and II, the mandible increases in length.

(2) During phase I with Herbst appliance, there is an increase in mandibular prognathism.

(3) During phase II with fixed appliance, the direction of growth of the mandible varies.

\section{Conflict of Interests}

The authors declare that there is no conflict of interests regarding the publication of this paper.

\section{Acknowledgment}

The authors would like to express their sincere thanks to Mr. Shadow Yeung for his valuable statistical guidance and support to the present study.

\section{References}

[1] U. Hägg, A. B. M. Rabie, M. Bendeus et al., "Condylar growth and mandibular positioning with stepwise vs maximum advancement," American Journal of Orthodontics and Dentofacial Orthopedics, vol. 134, no. 4, pp. 525-536, 2008.

[2] H. Pancherz, "The mechanism of Class II correction in Herbst appliance treatment: a cephalometric investigation," American Journal of Orthodontics, vol. 82, no. 2, pp. 104-113, 1982.

[3] K. L. D. Phan, M. Bendeus, U. Hägg, K. Hansen, and A. B. M. Rabie, "Comparison of the headgear activator and Herbst appliance-effects and post-treatment changes," The European Journal of Orthodontics, vol. 28, no. 6, pp. 594-604, 2006.

[4] B. Xu and H. Urban, "The study on treatment of Chinese children's Class II malocclusion by Herbst appliance," Chinese Journal of Stomatology, vol. 33, no. 2, pp. 113-115, 1998.

[5] J. R. Valant and P. M. Sinclair, "Treatment effects of the Herbst appliance," American Journal of Orthodontics and Dentofacial Orthopedics, vol. 95, no. 2, pp. 138-147, 1989.

[6] L. E. Johnston, "If wishes were horses: functional appliances and growth modification.," Progress in orthodontics, vol. 6, no. 1, pp. 36-47, 2005.

[7] M. C. Meikle, "What do prospective randomized clinical trials tell us about the treatment of Class II malocclusions? A personal viewpoint," European Journal of Orthodontics, vol. 27, no. 2, pp. 105-114, 2005.

[8] L. E. Johnston Jr., "Functional appliances: a mortgage on mandibular position," Australian Orthodontic Journal, vol. 14, no. 3, pp. 154-157, 1996.

[9] E. Marsico, E. Gatto, M. Burrascano, G. Matarese, and G. Cordasco, "Effectiveness of orthodontic treatment with functional appliances on mandibular growth in the short term," The American Journal of Orthodontics and Dentofacial Orthopedics, vol. 139, no. 1, pp. 24-36, 2011.

[10] G. J. Huang, "Functional appliances and long-term effects on mandibular growth," The American Journal of Orthodontics and Dentofacial Orthopedics, vol. 128, no. 3, pp. 271-272, 2005.

[11] C. Nelson, M. Harkness, and P. Herbison, "Mandibular changes during functional appliance treatment," American Journal of Orthodontics and Dentofacial Orthopedics, vol. 104, no. 2, pp. 153-161, 1993.

[12] W. R. Proffit, H. W. Fields Jr., and D. M. Sarver, Contemporary Orthodontics, Elsevier Health Sciences, Mosby, St. Louis, Mo, USA, 2007.

[13] J. F. Tulloch, W. R. Proffit, and C. Phillips, "Outcomes in a 2-phase randomized clinical trial of early Class II treatment," American Journal of Orthodontics and Dentofacial Orthopedics, vol. 125, no. 6, pp. 657-667, 2004.

[14] K. O’Brien, J. Wright, F. Conboy et al., "Early treatment for class II division 1 malocclusion with the Twin-block appliance: 
a multi-center, randomized, controlled trial," American Journal of Orthodontics and Dentofacial Orthopedics, vol. 135, no. 5, pp. 573-579, 2009.

[15] P. Banks, J. Wright, and K. O'Brien, "Incremental versus maximum bite advancement during twin-block therapy: a randomized controlled clinical trial," The American Journal of Orthodontics and Dentofacial Orthopedics, vol. 126, no. 5, pp. 583-588, 2004.

[16] J. Ghafari, F. S. Shofer, U. Jacobsson-Hunt, D. L. Markowitz, and L. L. Laster, "Headgear versus function regulator in the early treatment of Class II, division 1 malocclusion: a randomized clinical trial," The American Journal of Orthodontics and Dentofacial Orthopedics, vol. 113, no. 1, pp. 51-61, 1998.

[17] S. D. Keeling, T. T. Wheeler, G. J. King et al., "Anteroposterior skeletal and dental changes after early Class II treatment with bionators and headgear," American Journal of Orthodontics and Dentofacial Orthopedics, vol. 113, no. 1, pp. 40-50, 1998.

[18] M. A. Darendeliler, "Validity of randomized clinical trials in evaluating the outcome of Class II treatment," Seminars in Orthodontics, vol. 12, no. 1, pp. 67-79, 2006.

[19] H. Pancherz, "Vertical dentofacial changes during Herbst appliance treatment. A cephalometric investigation," Swedish Dental Journal, vol. 15, pp. 189-196, 1982.

[20] M. C. Wey, M. Bendeus, P. Li, U. Hägg, A. B. M. Rabie, and W. Robinson, "Stepwise advancement versus maximum jumping with headgear activator," The European Journal of Orthodontics, vol. 29, no. 3, pp. 283-293, 2007.

[21] U. Hägg, X. Du, and A. B. M. Rabie, "Initial and late treatment effects of headgear-Herbst appliance with mandibular stepby-step advancement," American Journal of Orthodontics and Dentofacial Orthopedics, vol. 122, no. 5, pp. 477-485, 2002.

[22] L. Wieslander, "Long-term effect of treatment with the headgear-Herbst appliance in the early mixed dentition. Stability or relapse?" American Journal of Orthodontics and Dentofacial Orthopedics, vol. 104, no. 4, pp. 319-329, 1993.

[23] J. Ömblus, O. Malmgren, H. Pancherz, U. Hägg, and K. Hansen, "Long-term effects of class II correction in Herbst and Bass therapy," The European Journal of Orthodontics, vol. 19, no. 2, pp. 185-193, 1997.

[24] E. Altenburger and B. Ingervall, "The initial effects of the treatment of Class II, division 1 malocclusions with the van Beek activator compared with the effects of the Herren activator and an activator-headgear combination," European Journal of Orthodontics, vol. 20, no. 4, pp. 389-397, 1998.

[25] H. Pancherz, "Treatment of Class II malocclusions by jumping the bite with the Herbst appliance: a cephalometric investigation," American Journal of Orthodontics, vol. 76, no. 4, pp. 423442, 1979.

[26] J. F. Tulloch, C. Phillips, and W. R. Proffit, "Benefit of early Class II treatment: progress report of a two-phase randomized clinical trial," American Journal of Orthodontics and Dentofacial Orthopedics, vol. 113, no. 1, pp. 62-74, 1998.

[27] M. Lai and J. A. McNamara Jr., "An evaluation of two-phase treatment with the Herbst appliance and preadjusted edgewise therapy," Seminars in orthodontics, vol. 4, no. 1, pp. 46-58, 1998.

[28] M. S. Cooke and S. H. Y. Wei, "Cephalometric standards for the southern Chinese," The European Journal of Orthodontics, vol. 10, no. 3, pp. 264-272, 1988.

[29] E. Hillesund, D. Fjeld, and B. U. Zachrisson, "Reliability of soft-tissue profile in cephalometrics," The American Journal of Orthodontics, vol. 74, no. 5, pp. 537-550, 1978.
[30] A. E. Athanasiou, R. Miethke, and A. J. van der Meij, "Random errors in localization of landmarks in postero-anterior cephalograms," Journal of Orthodontics, vol. 26, no. 4, pp. 273-284, 1999.

[31] B. Nelson, K. Hansen, and U. Hägg, "Class II correction in patients treated with Class II elastics and with fixed functional appliances: a comparative study," American Journal of Orthodontics and Dentofacial Orthopedics, vol. 118, no. 2, pp. 142-149, 2000.

[32] T. O. Nelson, "Analysis of facial growth utilizing elements of the cranial base as registrations," American Journal of Orthodontics, vol. 46, p. 379, 1960.

[33] B. Melsen, "The cranial base: the postnatal development of the cranial base studied histologically on human autopsy material," Acta odontologica Scandinavica, vol. 32, 1974.

[34] G. Dahlberg, "Statistical methods for medical and biological students," The British Medical Journal, vol. 2, no. 4158, pp. 358359, 1940.

[35] J. Y. C. Wu, U. Hägg, H. Pancherz, R. W. K. Wong, and C. McGrath, "Sagittal and vertical occlusal cephalometric analyses of Pancherz: norms for Chinese children," American Journal of Orthodontics and Dentofacial Orthopedics, vol. 137, no. 6, pp. 816-824, 2010.

[36] F. L. Bookstein, "Landmark methods for forms without landmarks: morphometrics of group differences in outline shape," Medical Image Analysis, vol. 1, no. 3, pp. 225-243, 1997.

[37] S. Baumrind and R. C. Frantz, "The reliability of head film measurements. 2. Conventional angular and linear measures," American Journal of Orthodontics, vol. 60, no. 5, pp. 505-517, 1971.

[38] A. Björk and M. Pallilng, "Adolescent age changes in sagittal jaw relation, alveolar prognathy, and incisal inclination," Acta Odontologica Scandinavica, vol. 12, no. 3-4, pp. 201-232, 1955.

[39] U. Hägg, E. L. K. Tse, A. B. M. Rabie, and W. Robinson, "A comparison of splinted and banded Herbst appliances: treatment changes and complications," Australian Orthodontic Journal, vol. 18, no. 2, pp. 76-81, 2002.

[40] H. Pancherz, "The Herbst appliance-its biologic effects and clinical use," American Journal of Orthodontics, vol. 87, no. 1, pp. 1-20, 1985.

[41] H. Pancherz and U. Hägg, "Dentofacial orthopedics in relation to somatic maturation. An analysis of 70 consecutive cases treated with the Herbst appliance," American Journal of Orthodontics, vol. 88, no. 4, pp. 273-287, 1985.

[42] U. Hägg and J. Taranger, "Maturation indicators and the pubertal growth spurt," American Journal of Orthodontics, vol. 82, no. 4, pp. 299-309, 1982.

[43] E. Herbst, "Dreissigjährige Erfahrungen mit dem Retentionsscharnier," Zahnärztl Rundschau, vol. 43, pp. 1515-1524, 1934.

[44] A. Chayanupatkul, A. B. M. Rabie, and U. Hägg, "Temporomandibular response to early and late removal of bite-jumping devices," The European Journal of Orthodontics, vol. 25, no. 5, pp. 465-470, 2003.

[45] J. W. P. Lau and U. Hägg, "Cephalometric morphology of Chinese with class II division 1 malocclusion," British Dental Journal, vol. 186, no. 4, pp. 188-190, 1999.

[46] M. Bendeus, U. Hägg, and B. Rabie, "Growth and treatment changes in patients treated with a headgear-activator appliance," The American Journal of Orthodontics and Dentofacial Orthopedics, vol. 121, no. 4, pp. 376-384, 2002. 
[47] X. Du, U. Hägg, and A. B. M. Rabie, "Effects of headgear Herbst and mandibular step-by-step advancement versus conventional Herbst appliance and maximal jumping of the mandible," The European Journal of Orthodontics, vol. 24, no. 2, pp. 167-174, 2002.

[48] K. O'Brien, J. Wright, F. Conboy et al., "Effectiveness of early orthodontic treatment with the twin-block appliance: a multicenter, randomized, controlled trial. Part 2: psychosocial effects," American Journal of Orthodontics and Dentofacial Orthopedics, vol. 124, no. 5, pp. 488-494, 2003. 


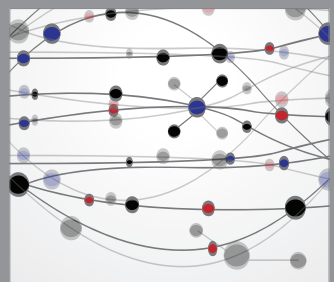

The Scientific World Journal
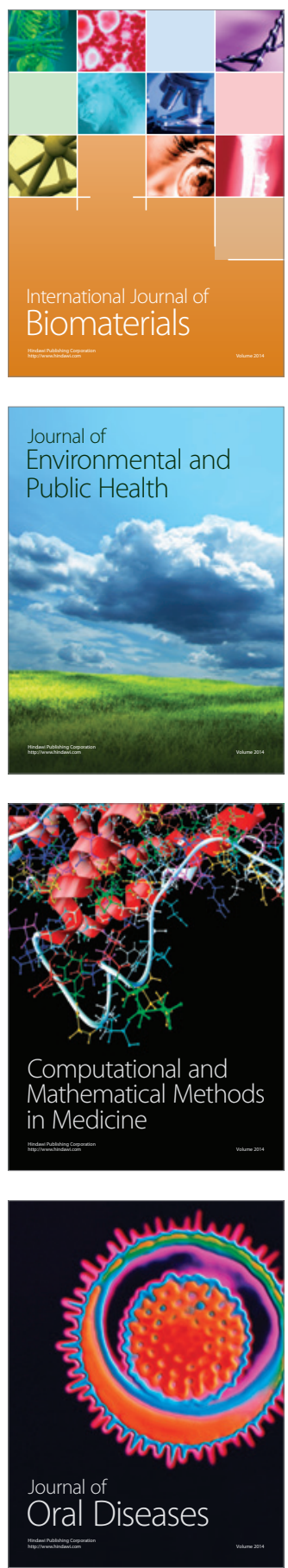
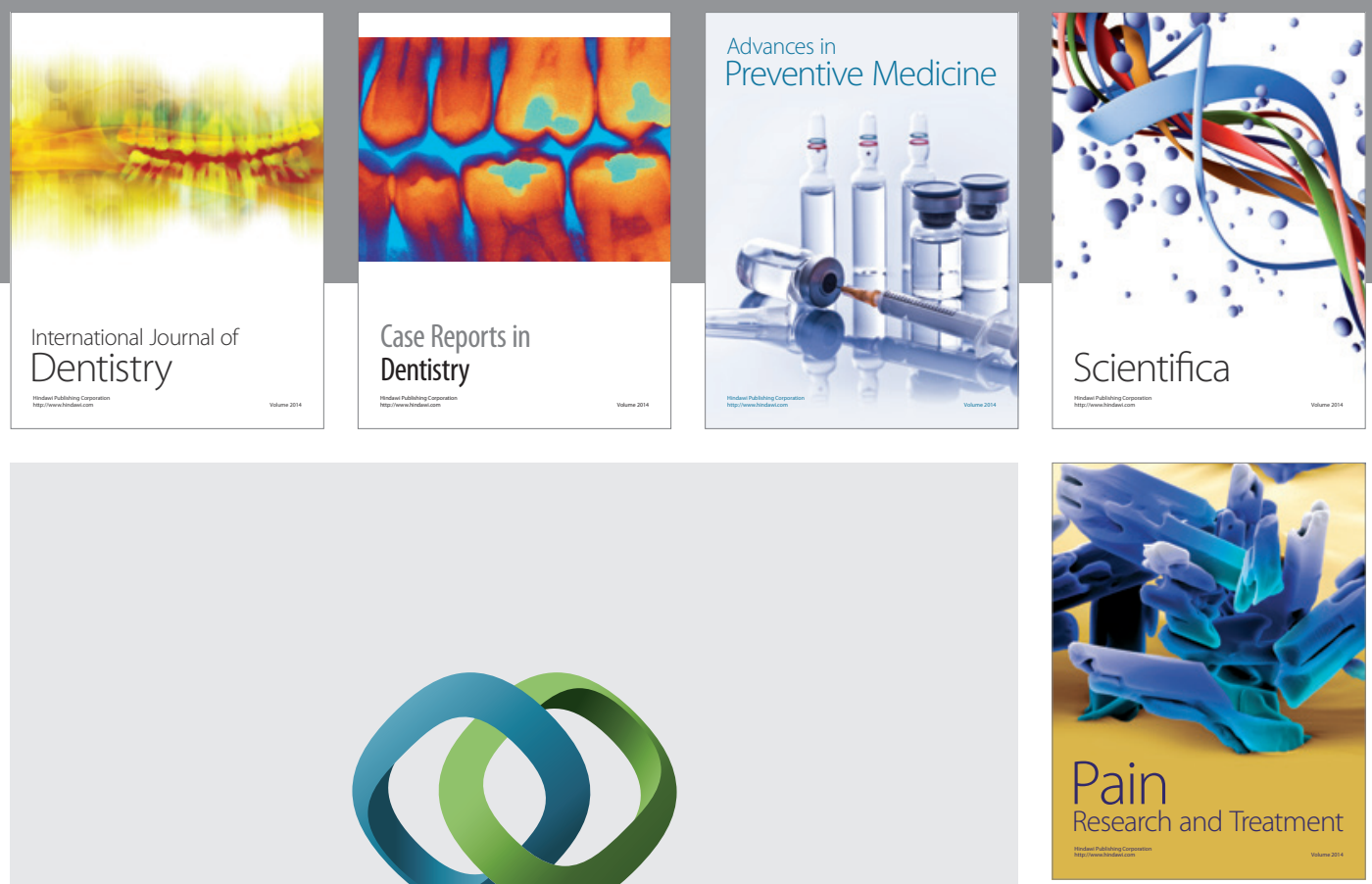

\section{Hindawi}

Submit your manuscripts at

http://www.hindawi.com
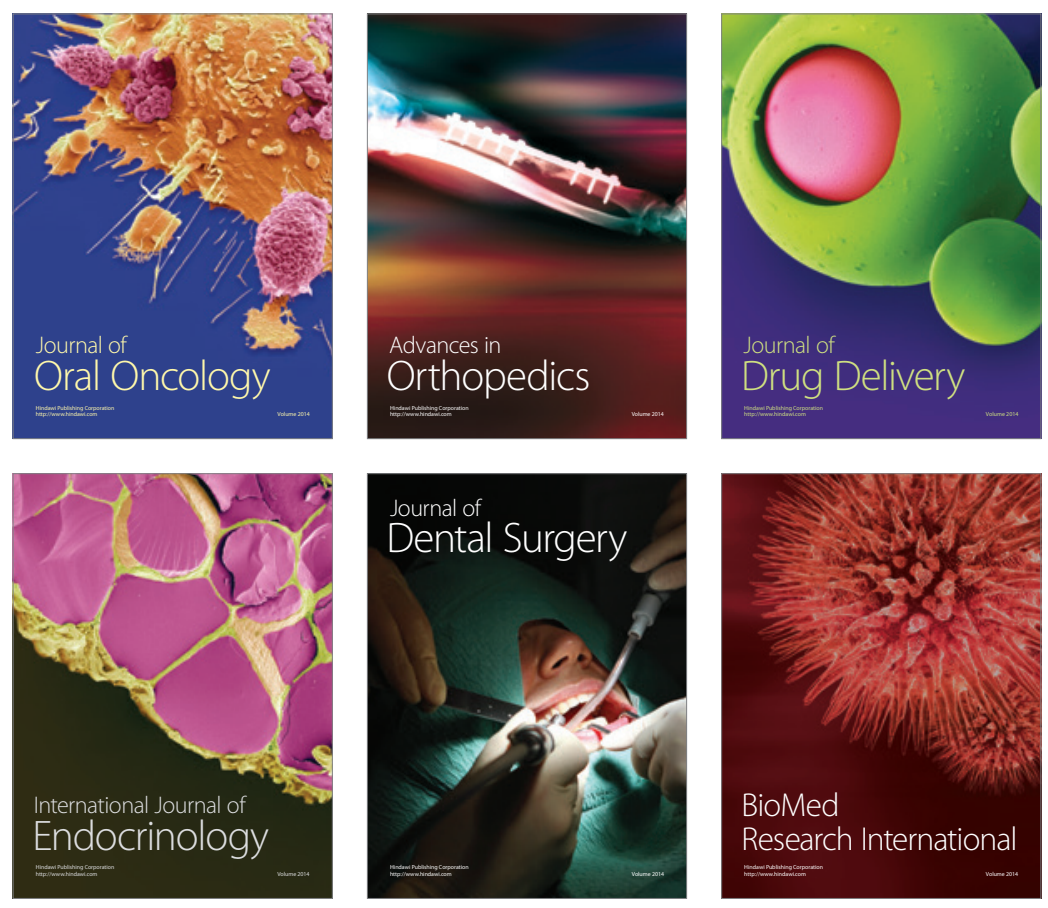

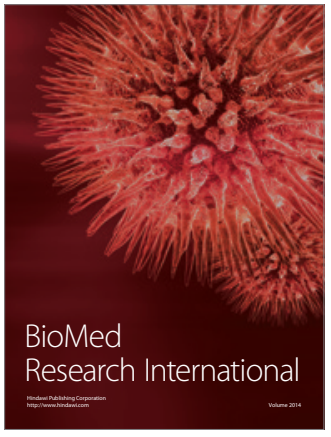

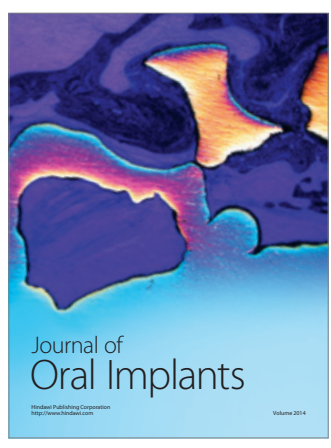
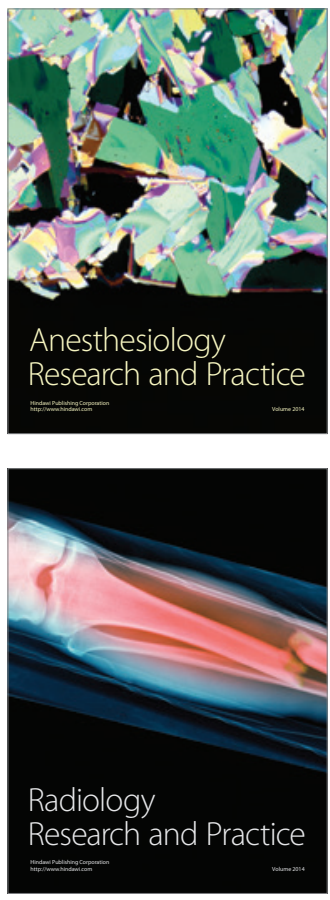